\title{
Hormone Receptors and Other Prognostic Factors in Breast Cancer in Cuba
}

\author{
Rosa Irene Álvarez Goyanes, Xiomara Escobar Pérez, Rolando Camacho Rodríguez, Maybi Orozco López, Sonia Franco \\ Odio, Leticia LLanes Fernández, Martha Guerra Yi, Cristina Rodríguez Padilla
}

Translated from Spanish and reprinted with permission from Cancerología, Journal of the Instituto Nacional de Cancerología, Mexico. Cancerología 3(2008):19-27. Original available at: http://www.incan.org.mx/revistaincan/elementos/documentosPortada/1215566785.pdf

\begin{abstract}
Clinical management of breast cancer, making a prognosis and deciding on treatment, currently depend on defining prognostic factors, especially hormone receptors (HR). In addition to confirming the heterogeneity of the disease, these biological parameters are indispensable tools for designing personalized treatment. In this study, 1509 tumors from Cuban women diagnosed with breast cancer were examined. Hormone receptor (HR) expression was determined and correlated with a group of prognostic factors, such as age, tumor size, histological type, nuclear grade, histological grade, number of metastatic axillary lymph nodes, and clinical stage. Estrogen receptor (ER) expression was associated with low nuclear grade and histological grade, and with smaller tumor size $(p<0.05)$. Analysis of age at the time of diag-
\end{abstract}

\section{INTRODUCTION}

Cancer is the second cause of death in Cuba and the first cause of potential years of life lost, and therefore the cause most affecting increase in life expectancy of Cubans at birth. Among Cuban women, breast cancer has the highest incidence (excluding skin tumors) and is the second leading cause of cancer mortality. Given that approximately 2500 new cases are diagnosed annually, and more than 1000 women die of breast cancer each year,[1] malignant breast tumors are considered a major health problem in the Cuban population.

With cancer, knowledge of the prognosis plays a fundamental role in medical decision-making and disease management.[2] Prognostic factors have been defined as variables that help explain heterogeneity in the course and development of a disease, regardless of the treatment administered, and that are associated with event-free and overall survival. [3] Once prognostic factors are identified, patients with similar characteristics can be classified for the purpose of selecting and administering therapeutic regimens of greater or lesser intensity. Analysis of factors predicting response to treatment likewise enables administration of specific therapies only in those patients expected to respond, thus avoiding harm with no benefit to patients lacking these factors. Treatments are becoming increasingly more personalized, significantly improving patients' quality of life.[4]

This study examined 1509 tumors from patients at 22 hospitals in 11 of Cuba's 14 provinces who were diagnosed with breast cancer between 2000 and 2006. The expression frequency of standard prognostic factors associated with tumors was analyzed: size, histological type and grade, nuclear grade, number of metastatic lymph nodes, clinical and post-surgical stage, and hormone receptor expression (HR). Age was the only patient-related prognostic factor analyzed. nosis showed that ER expression was greater in patients in the group aged $>50$ years $(p<0.05)$. In general, ER expression was greater in patients in earlier clinical stages $(p<0.05)$. With regard to $\mathrm{HR}$ expression, $53 \%$ of tumors in this sample were ER+ and $49 \%$ were PR+. In $38 \%$ of cases, both receptors were positive and in $28 \%$ both receptors proved negative. The ER+/PR- combination was observed in $23 \%$ of cases while only $11 \%$ exhibited the $\mathrm{ER}-/ \mathrm{PR}+$ combination. These findings indicate that approximately $72 \%$ of the tumors studied expressed some level of hormone dependency. This is the first report of HR expression in Cuba using immunohistochemical techniques and a representative sample of breast tumors diagnosed in different provinces around the country.

Keywords: Hormone receptors, breast cancer, prognostic factors

During the 1980s, biochemical methods for determining HR were standardized at the National Oncology and Radiobiology Institute (INOR) of Havana.[5] Results of work conducted during those years were, until now, the only report of $\mathrm{HR}$ expression in a $\mathrm{Cu}$ ban population sample.[5-10]

The objective of this study was to determine the frequency of HR expression in breast tumors in women from different regions of the country using immunohistochemical (IHC) techniques. Distribution of prognostic factors in the sample was also analyzed and correlated with estrogen receptor (ER) tissue expression.

\section{PATIENTS AND METHODS}

A total of 1509 breast tumor samples from patients who underwent surgery from 2000 through 2006 were received from medical centers located in different Cuban provinces. Samples were embedded in paraffin blocks containing a tumor fragment representative of the pathological-anatomical diagnosis, along with the corresponding glass slide stained with hematoxylin-eosin. The clinical or post-surgical stage of each case included in the study-according to clinical stage (TNM) classification valid at the time-was also provided with each sample on a data sheet containing information about the patient (name, age, medical record number) and the tumor (size, histological type, nuclear grade, histological grade, number of axillary lymph nodes examined and number of metastatic nodes).[11] Names of the attending physician, hospital and province were also recorded.

TNM stage was recorded for patients who received primary or neoadjuvant systemic treatment, and post-surgical stage (pTNM) for those who received initial surgical treatment. If information was incomplete, the case was included in the study and the data reported as "missing". IHC techniques were used to determine HR tissue expression.[12] Polysine ${ }^{\mathrm{TM}}$ glass slides (MenzelGlaser, Germany) were used. Antigen detection was carried out 
in a domestic steamer with a pH 6.0 citrate buffer. SP1 and SP2 monoclonal antibody (MAb) clones were used to detect estrogen receptors (ER) and progesterone receptors (PR), respectively. These MAbs were obtained pre-diluted.

An ultra-sensitive polyvalent detection system (MLINK), specific for mice and rabbit primary antibodies (Ab), was used, consisting of a secondary $\mathrm{Ab}$ marked with biotin and an enzyme/ anti-enzyme complex with streptavidin and peroxidase $(\mathrm{Px})$ molecules. Endogenous Px tissue activity was blocked with a diluted $3 \% \mathrm{H}_{2} \mathrm{O}_{2}$ solution. Enzymatic activity was revealed using a concentrated 3,3'-diaminobenzidine tetrahydrochloride (DAB) solution diluted in buffer substrate, and $0.6 \% \mathrm{H}_{2} \mathrm{O}_{2}$. Tissue immune reaction was viewed through a light field microscope (Leica, Germany).

The remaining reagents were obtained in ready-to-use packets. All reagents were supplied by Anacrom Diagnósticos, S.L. Seville, Spain.

Tissue samples were stained with Mayer's hematoxylin, and Eukitt (Kinder GmbH \& Co, Germany) was used for mounting the slides.

Two tissue sections were used in each experiment for quality and specificity control. Confirmed ER- or PR-positive tissue, along with an antibody unrelated to this antigen, or a phosphate-buffered saline (PBS) solution served as negative controls. Positivity criteria was $\geq 10 \%$ positive tumor cells.

\section{STATISTICAL ANALYSIS}

A descriptive analysis was made of the variables included in the study. Percentages were calculated for qualitative variables and the mean and standard deviation for quantitative variables. A Chisquare test was used to determine possible association between ER and the rest of the variables analyzed.

A significance level of $p<0.05$ was used in the statistical analyses. Data was analyzed with SPSS package (Statistical Program for the Social Sciences, Chicago, IL), version 11.0 for Windows.

\section{RESULTS}

The study sample is described in Table 1, which shows the percentage of useful samples of each of the prognostic factors analyzed. The sample size of each of the prognostic factors examined varied due to missing data. Useful data ranged from 837 (55.5\%) to $1509(100 \%)$.

As Figure 1 shows, the histological classification revealed a predominance of invasive duct carcinomas (IDC) $(73.9 \%)$ and invasive lobular carcinomas (ILC) (10\%). Special-type invasive carcinomas (medullary, mucinous, tubular and papillary carcinomas) accounted for $5 \%$ of the sample, while special clinical varieties, such as inflammatory carcinoma and Paget's disease, represented less than $1 \%$.

Intermediate and high nuclear and histological grade tumors predominated in the sample, with more grade II and III tumors observed. These morphological findings were associated with slower evolution and local recurrence. Little variation was observed in the size of the breast tumors examined. T1 tumors $(\leq 20 \mathrm{~mm}$ in diameter) were most frequent $(49.2 \%)$, followed by T2 (21-50 $\mathrm{mm}), 45.7 \%$ of the sample.
Table 1: Characteristics of the Study Sample

\begin{tabular}{|c|c|c|c|}
\hline & $\begin{array}{l}\text { Total } \\
\text { n (\%) }\end{array}$ & $\begin{array}{c}\text { Missing Data } \\
\mathbf{n}(\%)\end{array}$ & $\begin{array}{c}\text { Useful } \\
\text { Samples (\%) }\end{array}$ \\
\hline Sample & $1509(100.00)$ & & \\
\hline Histological Diagnosis & $1509(100.00)$ & $0(0.0)$ & 100.0 \\
\hline Nuclear Grade & $1009(66.90)$ & $500(33.1)$ & 66.9 \\
\hline $\begin{array}{l}\text { I } \\
\text { II } \\
\text { III }\end{array}$ & $\begin{array}{l}200(19.82) \\
518(51.30) \\
291(28.84)\end{array}$ & & \\
\hline Histological Grade & $944(62.60)$ & $565(37.4)$ & 62.6 \\
\hline $\begin{array}{l}\text { I } \\
\text { II } \\
\text { III }\end{array}$ & $\begin{array}{l}130(13.77) \\
518(54.87) \\
291(30.82)\end{array}$ & & \\
\hline Tumor Size & $837(55.50)$ & $672(44.5)$ & 55.5 \\
\hline $\begin{array}{l}\leq 20 \\
21-49 \mathrm{~mm} \\
\geq 50 \mathrm{~mm}\end{array}$ & $\begin{array}{r}412(49.20) \\
383(45.75) \\
42(5.01)\end{array}$ & & \\
\hline Metastatic Lymph Nodes & $1018(67.50)$ & $491(32.5)$ & 67.5 \\
\hline $\begin{array}{l}0 \\
1-3 \\
4-9 \\
\geq 10\end{array}$ & $\begin{array}{r}477(46.80) \\
262(25.73) \\
185(18.17) \\
94(9.23)\end{array}$ & & \\
\hline Clinical Stage ${ }^{\star *}$ & $1006(66.70)$ & $503(33.3)$ & 66.7 \\
\hline I & $232(23.06)$ & & \\
\hline II & $603(59.94)$ & & \\
\hline III & 155 (15.40) & & \\
\hline Age & $1229(71.50)$ & $280(18.5)$ & 81.5 \\
\hline$<50$ & $575(46.78)$ & & \\
\hline$\geq 50$ & $654(53.21)$ & & \\
\hline
\end{tabular}

* Special-type carcinomas

** TNM

Regarding the presence of metastatic axillary lymph nodes, $46.6 \%$ of tumors examined were node-negative (N0); $25.7 \%$ exhibited 1 to 3 nodes, and $27.4 \%$ exhibited 4 or more nodes.

Clinical stage analysis indicated that most patients in the study were in stages I and II (83\%), while $17 \%$ were in advanced stages of the disease.

Patients were divided into two age groups: aged $<50$ years $(46.8 \%)$ and aged $\geq 50$ years $(53.2 \%)$, which indirectly implied their menopausal status. ER expression was found in $53 \%$ of the breast tumors examined, while the remaining $47 \%$ did not exhibit this hormone receptor (Table 2). Correlation of this tumor marker with the other prognostic factors analyzed showed that as clinical stage, tumor size, nuclear grade and histological grade increased, ER positivity decreased in tumors studied $(p<0.05)$ (Table 3). At the same time, ER expression tended to decrease as the number of metastatic axillary lymph nodes

Figure 1: Distribution of Sample by Histological Type (\%)

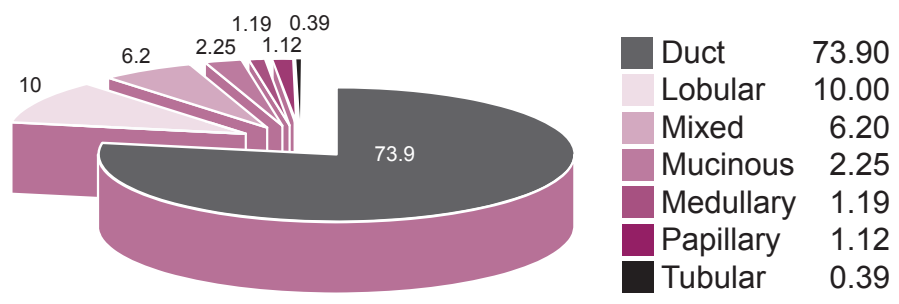


increased, although this association was not statistically significant. With regard to age, ER expression was greater in tumors in patients aged $\geq 50$ years $(p<0.05)$ (Table 3$)$.

Given the current value of PR as an independent predictive factor, determining expression of this marker was included in the study. Table 4 shows that of the 295 breast tumors analyzed, $49 \%$ were PR+.

In patients studied, 38\% exhibited tumors positive for both markers and $28 \%$ negative for both markers, while $23 \%$ were ER+/PR- and only 33 tumors (11\%) were ER-/PR+.

Table 2: Distribution of ER Expression in Breast Tumor Sample Studied

\begin{tabular}{c|c|c|c|c|}
\multirow{2}{*}{ ER } & $\mathbf{n}$ & $\begin{array}{c}\text { Positive } \\
\mathbf{n}(\%)\end{array}$ & $\begin{array}{c}\text { Negative } \\
\mathbf{n}(\%)\end{array}$ & $\begin{array}{c}\text { Not useful } \\
\mathbf{n}(\%)\end{array}$ \\
\cline { 2 - 5 } & 1509 & $743(53.0)$ & $658(47.0)$ & $108(7.15)$ \\
\hline
\end{tabular}

Table 3: Association of ER Tissue Expression with Essential Tumor-Related and Patient-Related Prognostic Factors

\begin{tabular}{|c|c|c|c|c|}
\hline \multirow[b]{2}{*}{ Prognostic Factor } & \multicolumn{4}{|c|}{ ER } \\
\hline & $\mathbf{n}$ & $\begin{array}{c}\text { Positive } \\
\text { n (\%) }\end{array}$ & $\begin{array}{c}\text { Negative } \\
\text { n (\%) }\end{array}$ & $\mathbf{p}$ \\
\hline Age (years) & & & & $0.040^{\star}$ \\
\hline$<50$ & 1174 & $266(48.3)$ & $284(51.6)$ & \\
\hline$\geq 50$ & & $360(57.6)$ & $264(42.3)$ & \\
\hline Tumor Size (mm) & 866 & & & $0.001^{*}$ \\
\hline$<20$ & & $261(65.2)$ & $139(34.7)$ & \\
\hline $21-49$ & & 211(53.6) & $182(46.3)$ & \\
\hline$\geq 50$ & & 27 (36.9) & $46(63.0)$ & \\
\hline Metastatic Lymph Nodes & 967 & & & 0.308 \\
\hline 0 & & $262(57.2)$ & $196(42.7)$ & \\
\hline $1-3$ & & $150(60.7)$ & $97(39.3)$ & \\
\hline $4-9$ & & $91(52.0)$ & $84(48.0)$ & \\
\hline$\geq 10$ & & $39(44.8)$ & $48(55.2)$ & \\
\hline Histological Grade & 915 & & & $0.014^{*}$ \\
\hline 1 & & $79(62.2)$ & $48(37.7)$ & \\
\hline II & & $288(56.8)$ & $219(43.2)$ & \\
\hline III & & $127(45.2)$ & $154(54.8)$ & \\
\hline Nuclear Grade & 977 & & & $0.001^{*}$ \\
\hline 1 & & $125(65.4)$ & $66(34.5)$ & \\
\hline II & & $291(58.1)$ & $210(41.9)$ & \\
\hline III & & $119(32.6)$ & $166(45.4)$ & \\
\hline Clinical stage ${ }^{* *}$ & 978 & & & $0.015^{\star}$ \\
\hline 1 & & $137(62.2)$ & $83(37.3)$ & \\
\hline II & & $339(58.1)$ & 245 (41.9) & \\
\hline III & & $58(34.5)$ & $110(65.5)$ & \\
\hline IV & & $5(31.2)$ & $11(68.8)$ & \\
\hline
\end{tabular}

${ }^{*} p<0.05$

${ }^{* *}$ TNM

Table 4: Distribution of PR Expression in Breast Tumors Studied

\begin{tabular}{c|c|c|c|c|}
\hline \multirow{2}{*}{ PR } & $\mathbf{n}$ & $\begin{array}{c}\text { Positive } \\
\mathbf{n}(\%)\end{array}$ & $\begin{array}{c}\text { Negative } \\
\mathbf{n}(\%)\end{array}$ & $\begin{array}{c}\text { Not Useful } \\
\mathbf{n}(\%)\end{array}$ \\
\cline { 2 - 6 } & 295 & $144(48.8)$ & $149(50.5)$ & $2(0.67)$ \\
\hline
\end{tabular}

Table 5: Correlation of HR Expression

\begin{tabular}{|c|c|c|c|c|}
\hline & \multicolumn{3}{|c|}{ PR } \\
\hline & & $\begin{array}{c}\text { Positive } \\
\text { n (\%) }\end{array}$ & $\begin{array}{c}\text { Negative } \\
\text { n (\%) }\end{array}$ & $\begin{array}{l}\text { Total } \\
\text { n (\%) }\end{array}$ \\
\hline \multirow{3}{*}{ ER } & Positive & $111(37.8)$ & $67(22.8)$ & $178(60.7)$ \\
\hline & Negative & $33(11.2)$ & $82(27.9)$ & 115 (39.2) \\
\hline & Total & 144 (49.1) & $149(50.8)$ & $293(100.0)$ \\
\hline
\end{tabular}

\section{DISCUSSION}

Breast cancer is a heterogeneous disease with a wide range of clinical manifestations and histological types. As a result, a patient's individual prognosis at time of diagnosis requires a detailed examination of as many clinical and pathologicalanatomical parameters as possible.

Prognostic factors in breast cancer are indicators that reflect the individual characteristics of the tumor and the patient.[13] Analysis and evaluation of these factors play a fundamental role in selection of the most effective cancer-specific therapy with the least unnecessary toxic effects produced by inadequate treatment regimens. By enabling prediction of the prognosis, these factors also contribute directly to prolonging survival of women diagnosed with breast cancer, and they have an impact, especially in the short term, on breast cancer mortality.[14-16]

Prognostic factors are used throughout the natural history of breast cancer-in chemoprevention; neoadjuvant, surgical and adjuvant treatment; as well as in recurrent disease. $[3,16,17]$ The association between breast cancer and the endocrine system was first established in 1896.[18] Since then, numerous scientific studies have demonstrated that endocrine therapy is an eligible treatment for patients with breast tumors expressing hormone receptors. Continued clinical research has provided evidence of new therapeutic treatments with greater benefits for patients. Hormone sensitive breast tumors are the target of luteinizing hormone, progestin, estrogen, androgen and, especially, estrogen antagonist analogues, such as tamoxifen, which has been used for decades and continues to be first-line treatment for HR-expressing primary and metastatic tumors.[19] Finally, aromatase inhibitors (Al) offer new therapeutic options, considered medically more potent with fewer side effects, leading to a major change in treatment options for postmenopausal patients with HR-expressing breast tumors.[20]

The clinical role of HR was first studied more than 30 years ago. Reports of the clinical importance of these molecules first appeared in 1975;[21] two years later, their association with the degree of tumor cell differentiation was confirmed, and they were considered independent prognostic factors.[22-25] Tumor size $(\mathrm{T})$, axillary nodal metastasis $(\mathrm{N})$ and distance metastasis $(\mathrm{M})$ are part of the breast cancer staging system known as TNM and are also tumor-associated predictive factors. The presence of metastatic axillary lymph nodes is the most relevant prognostic factor in primary breast tumors and is associated with poor prognosis: lower event-free and overall survival. Approximately $70 \%$ of these patients exhibit recurrent tumors after 10 years.[26,27] In the sample studied, $53 \%$ of patients were in this group, in which ER expression in breast tissue diminished as the number of metastatic lymph nodes rose, but the association between these prognostic factors was not statistically significant.

Tumor size continues to be an important predictive factor for patients both with and without positive axillary nodal metastasis. In the latter group, it is the strongest predictive variable for relapse,[28] accounting for $47 \%$ of patients in this study.

In relation to histological type: medullary, tubular, pure mucinous, and adenoid cystic carcinomas are considered low-grade tumors, associated with a low frequency or absence of axillary nodal metastasis. Although infrequency of these tumors makes quantitative analysis of their prognostic value difficult, they are classified 
among the tumors with better prognosis. The findings of this study coincide with those described by other authors regarding expression of these histological subtypes.[29]

Histological grade and nuclear grade are fundamental prognostic factors that over time have been shown to play an important role. High-grade tumors are generally associated with worse prognosis and a lower overall survival rate. It has been observed that $10 \%$ of patients with low-grade tumors relapse after five years, compared to $30 \%$ of patients with high-grade tumors.[30]

ER expression is higher in tumors in older patients.[31,32] Results of this study also showed higher ER expression in the group of patients aged $\geq 50$ years.

ER expression in the breast cancer sample analyzed was associated with good prognostic factors, such as low histological and nuclear grade, smaller tumor size and fewer metastatic axillary lymph nodes. In general, ER expression was higher in patients in earlier clinical stages of the disease. Some biological and socioeconomic factors, such as lifestyle, nutritional status and environmental exposure may influence ER expression in breast tumors. Positive ER expression differs among certain population groups. This factor was reported in $80.6 \%$ of Austrian women,[33] and in the United States, in $63.9 \%$ of white non-Hispanic women and $48.3 \%$ of black women.[34] At the same time, $53.4 \%$ of Thai women exhibit ER+ tumors, [35] and ER expression ranges between $53 \%$ and $61.6 \%$ in Chinese women, depending on their pre- and post-menopausal status.[36] In some countries, including Lebanon (43\%),[37] Iraq (34.2\%),[38] and Saudi Arabia (33.3\%)[39] in the Middle East, and Nigeria (24\%) in Africa,[40] HR expression is $<50 \%$. In this study, ER expression in Cuban women was $53 \%$, very similar to that reported for Thai and Chinese women.

Approximately $60 \%$ of women with ER+ tumors respond to hormone therapy.[41] Determination of the presence of this receptor is fundamental, not only for its prognostic value but also for its unquestionable predictive value of response over time to sustained cancer-specific therapy. The same has not occurred with PR, which lost its independent predictive value during the 1990s. $[42,43]$ Studies conducted by Baum et al, Bardou et al, and Cui et al in 2002, 2003 and 2005, associated the loss of PR expression with an increase in growth factor signals and aggressiveness of the tumor.[44-48] The existence of a number of ER- patients who respond to hormone therapy (approximately 8\%),[41] has renewed interest in studying the response range to this type of therapy. PR has now regained importance and been redefined as a predictive marker of ER activity, of growth factors, and also as a fundamental marker for indicating hormone therapy in breast cancer patients.[49,50]

PR tissue expression has been reported in $13.9 \%$ to $61.3 \%$ of primary and metastatic breast tumors.[35,36,40,51] In this study we observed $49 \%$ PR expression, very close to the upper limit of its expression range.

It has been well established that the presence of both HR in the same tumor increases the possibility of response to hormone treatment up to $80 \%$.[52] HR expression in breast tumor tissue in white women in the United States has been extensively studied; $63.9 \%$ of tumors are ER+/PR+ and $16.4 \%$ express at least one of these receptors, which predicts response to hormone treatment in $80.3 \%$ of patients. This study showed co-expression of both HR in $38 \%$ of breast tumors in Cuban women, while $34 \%$ express at least one receptor, indicating that $72 \%$ of our patients could benefit from hormone therapy.

In Cuba in 1982, Pascual et al produced the first report on HR expression in breast tumors using biochemical methods, showing $56 \%$ ER and $43 \%$ PR expression in a sample of patients at the National Oncology and Radiobiology Institute in Havana.

In the present study, using IHC techniques and a sample of almost four times as many breast tumors obtained from the principal sites of cancer incidence in the country, ER expression was $53 \%$ and PR $49 \%$, very similar to the values previously reported for both HR.

This study is the second report on hormone receptor expression in breast tumors conducted in Cuba, and the first report of HR expression in breast tumors using $\mathrm{IHC}$ techniques in a representative sample of women throughout the country. $-1 /$

\section{REFERENCES}

1. Reporte del Registro Nacional de Cáncer y del Anuario Estadístico. Cuba 2006.

2. Rizzi D.A.. Medical prognosis- some fundamentals. Theor Med 1993; 14: 365-375.

3. Stockler M., Boyd N., Tannock I. Guide to studies of diagnostic test, prognostic factors, and treatments, in Tannock I, Hill R (eds.): The basic science of oncology, 3d ed Toronto, McGraw-Hill 1998; 446-492.

4. Kummel S., Rezai M., Kimmig R., Schmid P. Dose-dense chemotherapy for primary breast cancer. Curr Opin Obstet Gynecol 2007; 19: 75-81.

5. Pascual M.R., Macias, A., Moreno, L., et al. Determinación de receptores hormonales de tumores mamarios humanos. Rev. Cub. Obstet. Ginecol 1981; 7:1

6. Lage A., Pascual, M.R.,et al. Factors associated with prognosis in human breast cancer: predictors for evolution and relapse. Neoplasm 1983; 30: 345.

7. Macias A., Pascual, M.R., Pérez, R., et al. Factors associated with prognosis in human breast cancer: progesterone receptors and clinical factors. Neoplasm 1983; 30: 232.

8. Pascual M.R., Rodríguez, M., Zayas, A., et al. Factors associated with prognosis in human breast cancer.II. Multivariate stratification analysis. Neoplasm 1983; 30: 485.

9. Pascual M.R., Rodríguez, M., Zayas, A., et al. Factors associated with prognosis in human breast cancer.III. Estradiol receptor and short term relapse. Neoplasm 1983; 30: 589.

10. Pascual, M.R., Macias, A., Lage, A., et al. Factors associated with prognosis in human breast cancer. V. The simultaneous use of estrogen and progesterone receptor measurements for prediction of short-term relapse. Neoplasm 1984; 32: 247

11. Sobin L.H., Wittekind C.H. TNM Classification of Malignant Tumours, 5ta ed: A John Wiley and Sons INC, Publication 1997; 123-130.

12. Llanes, L., Álvarez, R.I., Arango, M.C., et al. Relationship of IL-10 and tumoral markers in breast cancer patients. The Breast 2006; 15: 482-489.

13. Bailey, J.A. Concise dictionary of medical-legal terms. New York, The Parthanon Publishing Group 1998.
14. Willems A., Gauger K., Henrichs C. Antibody therapy for breast cancer. Anticancer Res 2005; 25: 1483-1489.

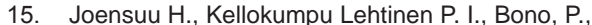
et al. Adjuvant docetaxel or vinorelbine with or without tratuzumab for breast cancer. N. Engl. J. Med 2006; 354: 809-820.

16. Kurebayashi, J. Current clinical trials of endocrine therapy for breast cancer. Breast Cancer 2007; 14: 200-214.

17. International Union Against Cancer. Prognostic Factors in Cancer, 2d ed, Gospodarowicz M.K., Henson D.E., Hutter R.V. P., O'Sullivan B., Sobin L.H., Wittekind Ch 2001.

18. Beatson, G.W. On the treatment of inoperable cases of carcinoma of the mamma: Suggestions for a new method of treatment with illustrative cases. Lancet 1896; 2: 104-107.

19. Budzar, A., Valero V., Theriault R.L., et al. Pathological complete response to chemotherapy in related with hormonal receptor status. Breast Cancer Res Treat 2003; 82: abstract; 302 
20. Mouridsen H., Gershanovich M., Sun Y., et al. Superior efficacy of Letrozole (Femara) versus Tamoxifen as first-line therapy for postmenopausal women with advanced breast cancer: Results of Phase III Study of the International Letrozole Breast Cancer Group. J Clin Oncol 2001; 19: 2596-2606.

21. Mass H., Engle B., Trams G. Steriod hormone receptors in human breast cancer and the clinical significance. J Steriod Biochem 1995; 6: 743-749.

22. Knight W.A., Livingston R.B., Gregoty B.H., et al. Estrogen receptor as a independent prognostic factor for early recurrence in breast cancer. Cancer Res 1977; 37: 4669-4771.

23. McCarty, K.S. Jr and McCarty, K.S. Sr. Steroid hormone receptors in the regulation of differentiation. Am J Pathol 1978; 86: 705-744.

24. Contesso G., Delarue J.C., Mouriesse H., et al. Anatomopathologie du cancer du sein et recepteurs hormnaux. Pathol Biol 1983; 31: 747-734.

25. Elston C.W., Blamey R.W., Johnson J., et al. The relationship of oestradiol receptors (RE) and histological tumours differentiation with prognosis in human primary breast carcinoma in Moridsen, Palshof, (eds): Breast Cancer: Experimental and clinical aspects. Oxford, Pergamon 1980;59-62.

26. Veronesi U., Galimberti V., Zurrida S., et al. Prognostic significance of number and level of axillary nodal metástasis in Breast cáncer. Breast 1993; 2: 224-228.

27. Jatoi I.,Hilsenbeck S.G., Clark G.M., et al. Significance of axillary lymph node metastasis in primary breast cancer. J Clin Oncol 1999; 17: 2334-2340.

28. Wilkinson N.W., Shahryarinejad, A., Winston, J.S., et al (2003) Concordance with breast cancer pathology reporting practice guidelines. J. Am. Coll. Surg 2003; 193: 38-43.

29. Rosen P.P. Rosen's Breast Pathology. Philadelphia: Lippincott-Raven 1997.

30. White J., Morrow, M., Moughan, J., et al. Compliance with breast conservation standards for patients with early stage breast carcinoma. Cancer 2003; 97: 893-904.

31. Thorpe S. Estrogen and progesterone receptor determinations in breast cancer. Technology, biology and clinical significance. Acta Oncol 1998; 27: 1-19.

32. Cheung K., Howell A., Robertson J. Preoperative endocrine therapy for breast cancer. EndocrRelate Cancer 2000; 7: 131-141.

33. Joslyn S.A. Hormone receptors in breast cancer: racial differences in distribution and survival. Breast Cancer Res Treat 2002; 73: 45-59.

34. Chu K.C., Anderson W.F., Fritz a., et al. Frequency distributions of breast cancer characteristics classified by estrogen receptors and progesterone receptor status for eight racial/ethnic groups. Cancer 2001; 92: 37-45.

35. Lertsanguansinchai $P$ Chottetanaprasith $T$. Chatamra K., et al: Estrogen and progesterone receptors status in Thai female breast cancer patients: an analysis of 399 cases at King Chulalongkorn Memorial Hospital. J med Assoc Thai 2002; 85, Suppl 1: s193-202.

36. Chow L.W., Ho P. Hormonal receptor determination of 1052 Chinese breast cancers. J Surg Oncol 2000; 75: 172-175.

37. Abadjian G., Antoun R. Breast carcinoma an evaluation of hormone receptors and pS2,erbB2, P-glycoprotein and Ki-67 markers. J Med Liban 1996; 44: 10-15.

38. al-Alwan N.A., al-Kubaisy W., al-Rawaq K. Assessment of response to tamoxifen among Iraqi patients with advanced breast cancers. East Mediterr Health J 2000; 6: 475-482.

39. Samir S. Amr, Abdul Rahman M. Sa'di., Fazal llahi., et al. Spectrum of breast diseases in Saudi Arab females: A 26 year pathological survey at Dhaaran Health Center. Ann Med Saudi 1995; 15:125-132.

40. Ikpatt O.F., Ndoma-Egba R.: oestrogen and progesterone receptors in Nigerian breast cancer: relationship to tumor histopathology and survival of patients. Cent Afr J Med 2003; 49: 122-126.

41. Maynard P.V., Davis C.J., Blamey R.W., et al Relationship between estrogen receptor content and histological grade in human primary breast tumors. Br J Cancer 1978; 38: 745-748.

42. Bezwoda W.R., Esser J.D., Dansey R., et al. The value of estrogen and progesterone receptor determinations in advanced breast cancer. Estrogen receptor level but not progesterone receptor level correlates with response to tamoxifen. Cancer 1991; 68: 867-872.

43. Early Breast Cancer Trialists Collaborative Group. Systemic treatment of early breast cancer by hormonal, cytotoxic, or immune therapy: 133 randomised trials involving 31 recurrences and 24000 deaths among 75000 women. Lancet 1992; 339: 75-81.

44. Baum M., Buzdar A.U., Cuzicck J., et al. Anastrozole alone or in combination with tamoxifen versus tamoxifene alone for adjuvant treatment of postmenopausal women with early breast cancer: First results of the ATAC randomizaed trial. Lancet 2002; 359: 2131-2139.

45. Baum M., Buzdar A. The current status of aromatase inhibitors in the management of Breast cancer. Sur Clin North Am 2003; 83: 973-994.

46. Bardou J.V., Arpino G., Elledge R.M, et al. Progesterone receptor status significantly improves outcome prediction over estrogen receptor status alone for adjuvant endocrine therapy in two large breast cancer databases. J. Clin Oncol 2003; 21: 1973-1979.

47. Cui X., Zhang P., Deng W., et al. Insuline like growth factor-1 inhibits progesterone receptor expression in breast cancer cells via the phosphatidylinositol 3 kinase/AKT/mammalian target of rapemycin pathway: Progesterone receptor as a potencial indicator of growth factor activity in breast cancer. Mol. Endocrinol 2003; 17 : 575-588

48. Cui X., Schiff R., Arpino G., Osborne C.K., Lee A. V. Biology of progesterone receptor loss in Breast Cancer snd its implications for endocrine therapy. J. Clin Oncol 2005; 23:7721-7735.

49. Konecny G., Pauletty G.,Pegram M., et al. Quantitative association between HER2/neu and steroid hormone receptors in hormone receptor positive primary breast cancer. J natl Cancer. Inst 2003; 95: 142-153.

50. Pozone F., Montemurro F., Maggiorotto C., et al. Clinical outcome of adjuvant endocrine treatment according to RP and HER2 status in early breast cancer. Ann Oncol 2006; 17: 1631-1636.

51. Stierer M., Rosen $\mathrm{H}$., Weber R et al Inmunohistochemical and biochemical measurement of estrogen and progesterone receptors in primary breast cancer. Correlation of histopathology and prognostic factors. Ann Surg 1993; 218: 13-21.

52. Early Breast Cáncer Trialist Collaborative Group (EBCTCG), Effects of chemotherapy and hormonal therapy for early breast cancer on recurrence and 15 year survival: an overview of the randomised trials. Lancet 2005; 365 : 1687-1717.

\section{THE AUTHORS}

Rosa Irene Álvarez Goyanes (Corresponding Author: ialvarez@infomed.sld.cu), Xiomara Escobar Pérez, Maybi Orozco López, Leticia LLanes Fernández, Martha Guerra Yi, Experimental Research, National Oncology and Radiobiology Institute, Havana, Cuba.

Rolando Camacho Rodríguez, Breast Cancer Service, National Oncology and Radiobiology Institute, Havana, Cuba.

Sonia Franco Odio, Pathological Anatomy Department, National Oncology and Radiobiology Institute, Havana, Cuba.

Cristina Rodríguez Padilla, Immunology Department, Faculty of Biology, Autonomous University of Nuevo Leon, Mexico. 